\title{
Revision of the East Asian Plagiophorus hispidus species group (Coleoptera: Staphylinidae, Pselaphinae, Cyathigerini)'
}

\author{
Hiroshi Sugaya ${ }^{2}$ \\ Systematic Entomology, Graduate School of Agriculture, Hokkaido University, Sapporo, \\ Japan 060-8589 \\ Shûhei Nomura \\ Department of Zoology, National Science Museum (Natural History), 3-23-1 Hyakunin-chô, \\ Shinjuku, Tokyo, Japan 169-0073

\section{Daniel Burckhardt}

Naturhistorisches Museum, Augustinergasse 2, Basel, Switzerland CH-4001

The Canadian Entomologist 136: 143-167 (2004)

\begin{abstract}
The hispidus species group is formed for four new species from East Asia of the genus Plagiophorus Motschulsky: P. hispidus sp. nov., P. hlavaci sp. nov., $P$. serratus sp. nov., and $P$. grandoculatus sp. nov. Uncoated specimens were examined using field-emission scanning electron microscopy, and micrographs of the holotypes are presented. Keys to the species groups of the genus occurring in East Asia and to the species of the hispidus group are given. The hispidus group is probably monophyletic, having peculiar spinous setae on the male metasternum. The chaetotaxy of the labrum and clypeus is useful for distinguishing species of Plagiophorus.
\end{abstract}

Sugaya H, Nomura S, Burckhardt D. 2004. Révision du groupe d'espèces de Plagiophorus hispidus de l'Asie de l'Est (Coleoptera : Staphylinidae, Pselaphinae, Cyathigerini). The Canadian Entomologist 136 : 143-167.

Résumé—-Le groupe d'espèces de hispidus du genre Plagiophorus Motschulsky réunit quatre espèces nouvelles récoltées en Asie de l'Est : $P$. hispidus sp. nov., $P$. hlavaci $\mathbf{s p}$. nov., $P$. serratus $\mathbf{s p}$. nov. et $P$. grandoculatus $\mathbf{s p . ~ n o v . ~ L e s ~ s p e ́ c i m e n s ~}$ ont été examinés au microscope électronique à balayage à émission de champs et on trouvera ici des microphotographies des holotypes. Des clefs d'identification permettent de distinguer les différents groupes d'espèces du genre présents en Asie de l'Est, de même que les espèces du groupe de hispidus. Le groupe de hispidus est probablement monophylétique, car les mâles possèdent des soies épineuses particulières sur le métasternum. La chétotaxie du labre et du clypéus est utile pour distinguer les espèces de Plagiophorus.

[Traduit par la Rédaction]

\section{Introduction}

Plagiophorus (Coleoptera: Staphylinidae, Pselaphinae, Cyathigerini) is a morphologically diverse genus, being especially variable in the number of antennomeres (6-11) and exhibiting remarkable sexual dimorphism. Species of the P. hispidus species group, which we deal with in this study, apparently have only 7 antennomeres (Figs. 3E, 5E,

${ }^{1}$ First part of revision of the East Asian genus Plagiophorus.

2 Corresponding author (e-mail: formosa@res.agr.hokudai.ac.jp). 
$7 \mathrm{E}, 9 \mathrm{E})$ and possess several secondary sexual characters such as the excavated club in males (Figs. 3E, 3F, 5E, 5F, 7E, 7F, 7G, 9E, 9F, 9G) and spinous setae on the metasternum of males (Figs. 4A, 4B, 6A, 6B, 8A, 8B, 10A, 10B). The functional significance of such secondary sexual characters is unclear because the bionomics of the beetles is poorly known. Beetles of this genus are usually found in leaf litter or under bark and are occasionally associated with ants.

There are 84 described species of Plagiophorus from the Oriental region (including China, Japan, and Korea), the Afrotropical region, and the Australasian region (including New Guinea and the Solomon Islands). According to Burckhardt and Löbl (2002), these beetles are abundant and species rich in the Oriental region, where there may be 400 species. Phylogenetic relationships among species in the genus have not been studied.

During the course of our study of material from East Asia, we have recognized seven species groups in the genus based mainly on the states of the following characters: (i) structure of the ventral surface of the maxillary palpomere III (Fig. 2D, mpIII), (ii) form of the antennal club of the male (Figs. 3E, 3F, 5E, 5F, 7E, 7F, 7G, 9E, 9F, 9G), (iii) structure of the metasternum of the male (Figs. 4A, 4B, 6A, 6B, 8A, 8B, 10A, $10 \mathrm{~B}$ ), and ( $v i$ ) presence or absence of a denticle on the pro- and meso-tibiae of the male (Figs. 2F, 2G). Characters $i$, iii, and vi are secondary sexual characters. The four characters are useful for systematic studies of the genus because the combination of character states is stable within each species group.

The objectives of the present study were to $(i)$ provide a key to the species groups of the genus present in East Asia, (ii) define the P. hispidus species group in East Asia, and (iii) describe four species of the hispidus group and present a key to the species.

\section{Historical review}

The genus Plagiophorus was established for two species of Pselaphinae from "Indes orientales" by Motschulsky (1851). The genus had been merely mentioned in catalogues (Raffray 1904, 1908, 1911; Newton and Chandler 1989) and left unrevised until Burckhardt and Löbl (2002) examined the type species. Raffray (1904, 1908, 1911) erroneously regarded the genus as a synonym of the genus Sathytes Westwood, 1870, which belongs to the tribe Batrisini. Newton and Chandler (1989) designated $P$. paradoxus as the type species of Plagiophorus and included the genus in the tribe Batrisini.

King (1865) established the genus Cyathiger based on a species from Australia. Subsequently, 48 species were described in Cyathiger. The tribe Cyathigerini was established to accept this genus by Schaufuss (1872).

Jeannel (1951) divided the genus Cyathiger into four genera, viz. Cyathiger King, Paracyathiger Jeannel, Denicyathiger Jeannel, and Cyathigerodes Jeannel, on the basis of the following characters: $(i)$ number of antennomeres and form of the antennal club, (ii) form of the male genitalia, and (iii) width of the frontal rostrum. Later, Jeannel (1961) described the genus Manuleiger from Sri Lanka. Jeannel (1952, 1953, 1954, 1956, 1957, 1959, 1960), Löbl (1964), Leleup (1974, 1975), and Nomura (1989) followed Jeannel's (1951) classification of the tribe Cyathigerini. On the other hand, Burckhardt (1985) and Chandler (1986) criticized Jeannel's classification. Burckhardt $(1985,1988 a, 1988 b)$, by implication, treated Cyathigerini as including only one genus, Cyathiger.

Recently, Burckhardt and Löbl (2002) redescribed P. paradoxus, the type species of Plagiophorus, and transferred Plagiophorus from the tribe Batrisini to the tribe Cyathigerini. They regarded Jeannel's (1951) system as superficial and synonymized 
the five genera (Cyathiger, Paracyathiger, Denicyathiger, Cyathigerodes, and Manuleiger) with Plagiophorus. Thus, Plagiophorus is now the only remaining genus in the tribe Cyathigerini.

In East Asia, only two species of the genus have been described: P. fujiyamai (Kubota, 1944) from Japan and P. matousheki (Löbl, 1964) from China. Nomura (1989) gave descriptions of both species from Japan; however, the species that he referred to as $P$. matousheki was misidentified. It is a previously undescribed species, which is described below as $P$. hispidus.

\section{Materials and methods}

\section{Repository abbreviations}

IZCAS Institute of Zoology, Chinese Academy of Sciences, Beijing, China

MHNG Muséum d'Histoire Naturelle, Genève, Switzerland

NHMB Naturhistorisches Museum, Basel, Switzerland

NMNS National Museum of Natural Science, Taichung, Taiwan

NSMT National Science Museum (Natural History), Tokyo, Japan

SEHU Systematic Entomology, Hokkaido University, Sapporo, Japan

cHS Private collection of H Sugaya, Hokkaido University, Sapporo, Japan

\section{Methods of examination}

We examined specimens mainly by field-emission scanning electron microscopy (FESEM, JEOL JSM-6301F). The specimens were not coated and were digitalmicrographed from various angles. We compiled the FESEM micrographs and measured body parts using Adobe Photoshop ${ }^{\circledR}$. Measurements of body length and width were made with a stereo microscope (Olympus SZ40). Scale bars in all figures are in micrometres.

For FESEM observations, specimens were washed in an ultrasonic cleaner using $30 \%$ ammonia for about $10 \mathrm{~s}$, heated in $90 \%$ lactic acid at $60{ }^{\circ} \mathrm{C}$ for about $30 \mathrm{~min}$, soaked in $30 \%$ hydrogen peroxide for about $5 \mathrm{~min}$, and rinsed in absolute ethanol for $>2 \mathrm{~min}$. The SEM was set with a working distance of $39 \mathrm{~mm}$ and an accelerating voltage of $0.7-1.0 \mathrm{kV}$.

\section{Terminology}

The terminology adopted in the present study mostly follows Chandler (2001). Abbreviations employed herein are as follows: TL, total length ( $\mathrm{HL}+\mathrm{PL}+\mathrm{EL}+\mathrm{AL})$; HL, maximum length of head (from apical margin of frontal rostrum to posterior margin of tempora); PL, maximum length of pronotum; EL, maximum length of elytra; AL, maximum length of abdomen; HW, maximum width of head (not including eyes); FW, maximum width of frontal rostrum; PW, maximum width of pronotum; EW, maximum width of elytra; AW, maximum width of abdomen; dcs, distance between clypeal setae (Figs. 3C, 5C, 7C, 9C, 11); mp, median projection of labrum (Fig. 3C); ip, inside projection of labrum (Fig. 3C); op, outside projection of labrum (Fig. 3C).

\section{Notes on sexual dimorphism}

The metasternal setae may be useful for keeping the male mounted on the female during copulation. Males of the genus Scaphidium Olivier (Scaphidiinae) have long setae forming a patch on the mesal area of the metasternum. Observation of copulating 
pairs has suggested that these setae are used to keep the male body in a stable position on the convex dorsum of the female. Similar setae occur on other Scaphidiinae genera such as Euscaphidium Achard, Cerambyciscapha Pic, and Diatelium Pascoe (Leschen and Löbl 1995), which also have plump bodies like the genus Plagiophorus.

Some species groups of the genus Plagiophorus, including the hispidus group, exhibit remarkable sexual dimorphism in the antennal club, which is broadly excavated on the dorsal side in the male. During copulation, the pair might be held together by insertion of the female antennal club into the male excavation (Raffray 1908). In fact, in all species observed, the female club fits easily into the excavation of the male club. Such an exact agreement in size cannot be coincidental, and the hypothesis should be tested.

\section{Chaetotaxy of labrum and clypeus}

Sawada (1972) introduced labral chaetotaxy into one classification of the subfamily Aleocharinae and demonstrated that it is useful for identifying species including both of the sexes and local forms. Recently, Ohishi (2001) also suggested the usefulness of the labral chaetotaxy in the classification of the Pselaphinae, though he made no mention of infraspecific variation. Our study of the genus Plagiophorus shows that the labral chaetotaxy and the distance between the clypeal setae are useful for identifying species, sexes, and local forms in this genus. Our examinations have revealed that the combined chaetotaxy of the labrum and clypeus is useful in recognizing species in many Pselaphinae genera such as Nipponozetus Coulon, Philoscotus Sawada, Bryaxis Kugelann, Triomicrus Sharp, Tribasodes Jeannel, Batrisceniola Jeannel, Pselaphogenius Reitter, Hirashimanymus Nomura, Apharinodes Raffray, and Lasinus Sharp.

The usefulness of the chaetotaxy of the labrum and clypeus in the genus Plagiophorus is documented here for the first time. The two characters used are the distances between the three principal setae $(a, b, c)$ of the labrum, which form a triangle (the setal triangle), and the distance between the two setae on the clypeus (dcs) (Figs. 3C, 5C, 7C, 9C, 11). After examination of species representing all the species groups recognized in our study, we found that the relative position of these setae were useful in distinguishing species. In $P$. hispidus, these characters vary slightly between the sexes and between the islands (Ishigaki Shima and Iriomote Jima) (Fig. 11). In particular, the female specimens from Iriomote Jima (Fig. 11D) are somewhat different from the others (Figs. 11A-11C); des is shorter and principal seta $b$ is located more apically than $c$. These differences, however, are much smaller than those between other species.

\section{Systematics}

\section{Genus Plagiophorus Motschulsky, 1851}

Plagiophorus Motschulsky, 1851: 496. Newton and Chandler, 1989: 39.

Type species: Plagiophorus paradoxus Motschulsky, by subsequent designation.

Cyathiger King, 1865: 173. Burckhardt and Löbl, 2002: 400 (as junior synonym of Plagiophorus Motschulsky).

Type species: Cyathiger punctatus King, by monotypy.

Paracyathiger Jeannel, 1951: 109. Burckhardt and Löbl, 2002: 400 (as junior synonym of Plagiophorus Motschulsky).

Type species: Cyathiger heterocerus Raffary, by original designation.

Denicyathiger Jeannel, 1951: 109. Burckhardt and Löbl, 2002: 400 (as junior synonym of Plagiophorus Motschulsky).

Type species: Cyathiger bironis Raffary, by original designation. 
Cyathigerodes Jeannel, 1951: 109. Burckhardt and Löbl, 2002: 400 (as junior synonym of Plagiophorus Motschulsky).

Type species: Cyathigerodes machadoi Jeannel, by original designation.

Manuleiger Jeannel, 1961: 449. Burckhardt and Löbl, 2002: 400 (as junior synonym of Plagiophorus Motschulsky).

Type species: Manuleiger remyi Jeannel, by original designation.

\section{Diagnosis}

The genus is distinguished from all other Pselaphinae genera by the combination of the following character states: (i) dorsal surface densely covered with punctures, (ii) antenna with 6-11 antennomeres, (iii) terminal antennomere much larger than each of the preceding antennomeres, (vi) 4th to 7 th abdominal tergites fused to form a composite tergum, and $(v) 4$ th to 7 th abdominal sternites fused to form a composite sternum.

\section{Remarks}

The genus Plagiophorus is characterized by the composite tergum formed by the fused 4th to 7th abdominal tergites and the composite sternum formed by the fused 4th to 7th abdominal sternites. These autapomorphies support its monophyly.

We recognize seven species groups of East Asian species of Plagiophorus and have tried to assign other species to these species groups. We have found that most of the described species of the genus from other regions are assignable to one of the species groups recognized in our study.

\section{Key to East Asian species groups of Plagiophorus (male)}

1. Maxillary palpomere III lacking granulae on ventral surface; mesotibia with a denticle; mesofemur lacking projection . . . . . . . . . . . . . . . . . . . . . . . . . . . . . . . . . . . 2

- Maxillary palpomere III with granulae on ventral surface; mesotibia lacking denticle; mesofemur with 1 or a few projections . . . . . . . . . . . . . . . . . . . . . . . . . . . . . . 6

2. Metasternal apex with a pair of sharp projections; apparently 11 antennomeres . . . . . . . A group

- Metasternal apex lacking sharp projections; apparently 7 antennomeres . . . . . . . . . . . . . 3

3. Antennal club lacking excavation; protibia each with a denticle . . . . . . . . . . . . . . . . 4

- Antennal club with an excavation; protibia with or lacking denticle . . . . . . . . . . . . . . . . 5

4. Antennomere III with 2 distinct sutures; frontal rostrum subparallel-sided; sternite IX partly visible externally . . . . . . . . . . . . . . . . . . . . . . . . . . fujiyamai group

- Antennomere III with 3 distinct sutures; frontal rostrum dilated posteriorly; sternite IX not visible externally. . . . . . . . . . . . . . . . . . . . . . . . . . . . B group

5. Metasternum with spinous setae; inner margin of excavation of antennal club simple, lacking projection and fringe; protibia with a denticle . . . . . . . . . . . . . . . . . . . . hispidus group

- Metasternum lacking spinous setae; inner margin of excavation of antennal club with projection and fringe; protibia lacking denticle . . . . . . . . . . . . . . . . . . . . . . . . . C group

6. Antennal club lacking distinct excavation; apparently 10 antennomeres . . . . . . . . . . D group

— Antennal club with a distinct excavation; apparently 7 antennomeres . . . . . . . . . . . E group

\section{Remarks}

A group, B group, C group, D group, and E group will be named in future studies.

\section{The hispidus group}

Species included: P. hispidus, P. hlavaci, P. serratus, and P. grandoculatus. 


\section{Key to East Asian species of the hispidus group (male)}

1. Frontal rostrum lacking longitudinal groove (Figs. 3A, 5A) . . . . . . . . . . . . . . . . . . 2

- Frontal rostrum with longitudinal groove (Figs. 7A, 9A) . . . . . . . . . . . . . . . . . . . 3

2. Each elytron with basal fovea (Fig. 3D, arrow); eye with 2 to 4 facets (Fig. 3B, arrow); inner surface of antennal club with longitudinal stria (Fig. 3F, arrow 1) . . . . . . . . . . . . . . . . P. hispidus

- Each elytron with 2 basal foveae (Fig. 5D, arrows); eye with about 12 facets (Fig. 5B, arrow); inner surface of antennal club lacking longitudinal stria (Fig. 5F); antennomere III produced and angulate on inner margin, thus nearly pentagonal in profile (Fig. 5E, arrow; Fig. 5H); protibia with outer margin strongly constricted at middle (Fig. 5I, arrow) . . . . . . . . . . . . . . . . . . . . P. hlavaci

3. Each elytron with basal fovea (Fig. 7D, arrow); eye with about 7 facets (Fig. 7B, arrow); inner surface of antennal club with longitudinal stria (Fig. 7F, arrow); sternal carina with 4 teeth (Fig. 8D, arrow)

P. serratus

- Each elytron with 2 basal foveae (Fig. 9D, arrows); eye reniform with about 40 facets (Fig. 9B); inner surface of antennal club lacking longitudinal stria (Fig. 9F); sternal carina with a weak tooth (Fig. 10D)

P. grandoculatus

\section{Diagnosis}

The hispidus group is distinguished from the other species groups of the genus Plagiophorus by the combination of the following character states in the male: (i) maxillary palpomere III reticulate on ventral surface (Fig. 2D, mpIII), (ii) excavation of club lacking projection and fringe on inner margin (Figs. 3E, 5E, 7E, 9E), (iii) metasternum with 1-2 pairs of setigerous patches (Figs. 4A, 4B, 6A, 6B, 8A, 8B, 10A, 10B), and (vi) pro- and meso-tibia each with a denticle (Figs. 2F, 2G).

\section{Description}

Male and female. Body. Dark reddish brown, dorsal surface with dense punctures and short and flattened setae (Figs. 1, 2A). Head (Figs. 2B, 2C, 3A, 3B, 5A, 5B, 7A, 7B, 9A, 9B). Frontal rostrum narrower than postgena; clypeus with pair of setae (Figs. 3C, 5C, 7C, 9C); gena well expanded, with obtuse anterolateral corner; vertexal fovea small, situated posterior to middle; postgena broad and rounded; eye situated before vertexal fovea; ocular-mandibular carina weak (Fig. 2B, omc); ventrolateral margin not carinate (Fig. 2B, vm); gula with blunt median gular spine (Fig. 2C, mgs), lacking median gular carina. Labrum: 2 pairs of projections (Fig. 3C, op, ip; Figs. 5C, 7C, 9C) and 1 median projection on anterior margin (Fig. 3C, mp; Figs. 5C, 7C, 9C), with 3 distinct principal setae labelled $a, b$, and $c$ from inside to outside (Figs. 3C, 5C, 7C, 9C, 11). Maxillary palpus (Fig. 2D): 3 segments; palpomere I dilated apically; palpomere II smallest; palpomere III (Fig. 2D, mpIII) largest and fusiform, reticulate and sparsely pubescent on ventral surface, with palpal cone. Antenna (Figs. 3E, 5E, 7E, 9E): shorter than HL + PL, twisted, thick, apparently with 7 antennomeres; antennomere I greater in length than width, weakly dilated apically; antennomere II shorter and narrower than I; antennomere III with 2 transverse sutures near base; antennomeres IV, $\mathrm{V}$, and VI subequal in shape and size; antennomere VII largest, forming large club, with basal suture (Fig. 3E, bs). Thorax. Pronotum: longer than head, broadest at middle, with small median antebasal fovea and small lateral antebasal foveae. Prosternum: with small lateral procoxal foveae. Metasternum (Figs. 4A, 4C, 6A, 6C, 8A, 8C, 10A, 10C): with median metasternal fovea (Fig. 4A, mmtf), with depression (Figs. 4C, 6C, 8C, 10C, md) around lateral mesocoxal fovea (Figs. 4C, 6C, 8C, 10C, lmcf). Elytra: each elytron with basal ridge nearly horizontal, with 1 or 2 basal fovea(e) (Figs. 3D, 5D, 7D, 9D, arrow(s)). Leg: metatibia more or less sinuate. Abdomen. Composite tergum (tergites IV to VII) rounded posteriorly; composite sternum (sternites IV to VII) concave 


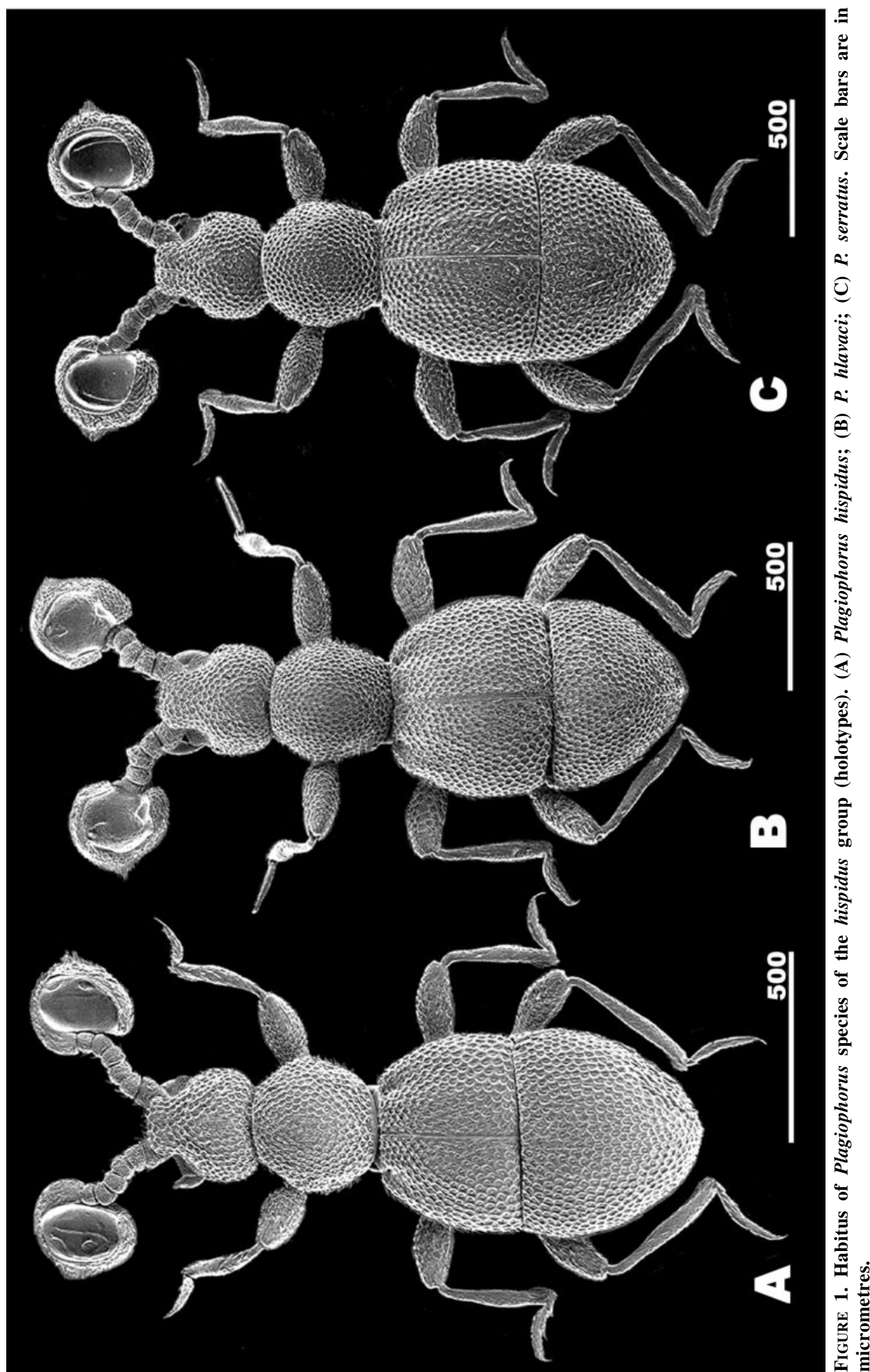

Downloaded from https:/www.cambridge.org/core. University of Basel Library, on 10 Jul 2017 at 16:20:22, subject to the Cambridge Core terms of use, available at https:/www.cambridge.org/core/terms. https://doi.org/10.4039/n03-001 
medially, with deep basal cavity; sternal carina (Fig. 2E, sc; Figs. 4D, 6D, 8D, 10D, arrow) with 1 or more teeth.

Sexual characters. Male. Antenna (Figs. 3E, 5E, 7E, 9E): antennomere VII distinctly larger than that of female; bowl-shaped; inner surface deeply excavated (Fig. 3E, is); inner margin of excavation simple, lacking projection and fringe (Fig. 3E, im). Metasternum: with 1 pair or 2 pairs of setigerous patches (Figs. 4A, 6A, 8A, 10A, sp), the setae being spinous (Figs. 4B, 6B, 8B, 10B). Leg: pro- and meso-tibia each with small apical denticle on inner margin (Figs. 2F, 2G, arrow). Abdominal composite sternum: flattened on posterior portion; tergite VIII convex in medioapical part; sternite VIII transverse, with a pair of long basal stalks; sternite IX semicircular, posterior half visible externally. Genitalia (Figs. 4E-4I, 6E-6I, 8E-8I, 10E-10I): median lobe of aedeagus consisting of basal bulb (Fig. 4F, bb), inner sclerite (Fig. 4H, is), and apical process (Fig. 4H, ap); inner sclerite arising from inside of basal bulb and apical process from outside of basal bulb. Parameres (Fig. 4F, lp, rp): asymmetrical, weakly sclerotized. Female. Antenna: antennomere VI larger than that of male; antennomere VII (Figs. 3G, 5G) cordiform, lacking excavation. Metasternum: lacking setigerous patches. Leg: pro- and meso-tibia lacking denticle. Abdominal composite sternum: weakly convex on posterior portion; tergite VIII triangular, weakly convex, arcuate posteromedially; sternite VIII arcuate, with semicircular internal lobe.

\title{
Remarks
}

The hispidus group is unique in having spinous setae on the male metasternum, an apomorphy shared by the species of the group, which therefore should be monophyletic.

\section{Plagiophorus hispidus sp. nov.}

\author{
(Figs. 1A, 2, 3, 4, 11, 12)
}

Paracyathiger matousheki: Nomura 1989: 529, nec Löbl, 1964: 297 (misidentification).

\section{Type material}

Holotype: male (Figs. 1A, 2, 3A-3F, 4). JAPAN. The Ryukyus. Ishigaki Shima: Omoto-dake, $300 \mathrm{~m}$ alt., 18-19.iii.2002, H Sugaya (SEHU). Paratypes. Ishigaki Shima: 1 male, same locality as holotype but 22.iii.1984, S Nomura (NSMT). 1 male, 3 females, same locality as holotype but 9.iv.1986, S Nomura (NSMT). 2 males, same data as holotype but 11.iii.1986, S Nomura (NSMT). 3 males, 1 female, same locality as holotype but 14.x.1988, M Sakai (NSMT). 2 males, 4 females, same data as holotype (cHS, NHMB). Iriomote Jima: 1 female, Noyashi, 19.vii.1969, K Ishikawa (MHNG). 3 males, 1 female, Komi, 15-16.iii.2002, H Sugaya (cHS, NHMB, NMNS).

\section{Etymology}

In Latin hispidus means setal, referring to the presence of the spinous setae on the male metasternum.

\section{Diagnosis}

This species is distinguished from the other members of the species group by the combination of the following character states in the male: $(i)$ frontal rostrum lacking longitudinal groove (Fig. 3A), (ii) eye with 2 to 4 facets (Fig. 3B, arrow), (iii) inner surface 
Table 1. Measurements of holotypes of the new Plagiophorus species of the hispidus group (mm).

\begin{tabular}{lcccccccccc}
\hline & TL & HL & PL & EL & AL & HW & FW & PW & EW & AW \\
\hline P. hispidus & 1.42 & 0.30 & 0.31 & 0.35 & 0.46 & 0.30 & 0.15 & 0.35 & 0.52 & 0.53 \\
P. hlavaci & 1.65 & 0.33 & 0.38 & 0.51 & 0.43 & 0.38 & 0.18 & 0.40 & 0.68 & 0.64 \\
P. serratus & 1.78 & 0.37 & 0.41 & 0.54 & 0.46 & 0.35 & 0.20 & 0.46 & 0.74 & 0.71 \\
P. grandoculatus & 1.66 & 0.36 & 0.38 & 0.52 & 0.40 & 0.34 & 0.19 & 0.40 & 0.73 & 0.67
\end{tabular}

NOTE: TL, total length; HL, maximum length of head; PL, maximum length of pronotum; EL, maximum length of elytra; AL, maximum length of abdomen; HW, maximum width of head; FW, maximum width of frontal rostrum; PW, maximum width of pronotum; EW, maximum width of elytra; AW, maximum width of abdomen.

of antennal club with a longitudinal stria (Fig. 3F, arrow 1), (vi) elytra shorter than abdomen (Fig. 1A), and (v) each elytron with a basal fovea (Fig. 3D, arrow).

\section{Description}

Male and female. Body (Figs. 1A, 2A). Length, 1.3-1.4 mm; width, 0.4-0.5 mm (see Table 1 for measurements of holotype); broadest at anterior $1 / 3$ of abdomen, dorsal surface shallowly favose-punctured. Head (Figs. 3A, 3B). As wide as long (HW/HL = 1.00 ), broadest at posterior $1 / 3$; frontal rostrum flat on median part, relatively narrow $(\mathrm{HW} / \mathrm{FW}=2.00)$, arcuate on anterior margin; gena well expanded laterally; eye (Fig. 3B, arrow) reduced, with 2 to 4 facets. Labral and clypeal chaetotaxy (Fig. 3C): setal triangle with side $a-c$ longer than dcs; side $b-c$ shortest. Labrum: mp (Fig. 3C) and ip (Fig. 3C) less projecting than op (Fig. 3C). Maxillary palpomere III (Fig. 2D, mpIII): about 2.1 times as long as wide, distinctly reticulate on ventral surface. Thorax. Pronotum: longer than head $(\mathrm{PL} / \mathrm{HL}=1.03)$, broader than long $(\mathrm{PW} / \mathrm{PL}=1.13)$. Metasternum (Fig. 4A): short, distance from metasternal process (Fig. 4A, mp) to metasternal apex (Fig. 4A, ma) about 2.9 times as long as longitudinal diameter of median metasternal fovea; metasternal process narrow and rounded; lateral mesocoxal foveae (Fig. 4C, lmcf) almost circular; depression around lateral mesocoxal fovea (Fig. 4C, md) not extending posteriorly. Elytra: shorter than abdomen (EL/AL = 0.76), broader than long $(\mathrm{EW} / \mathrm{EL}=1.49)$, broadest at posterior $1 / 3$, weakly convex, constricted at anterior part, each elytron with a basal fovea (Fig. 3D, arrow); hind wing reduced. Leg: metatibia weakly sinuate. Abdomen. Composite tergum wider than long $(\mathrm{AW} / \mathrm{AL}=1.15)$, broadest at basal $1 / 3$, constricted at base; sternal carina (Fig. 4D) with small tooth located at apical $1 / 3$.

Sexual characters. Male. Antenna (Fig. 3E): antennomere III about 1.5 times as wide as long, with 2 indistinct sutures; antennomere VI smallest; antennomere VII (Fig. 3F) about 1.2 times as long as wide, reniform, its excavation opened basimedially, inner surface (Fig. 3E, is) almost glabrous, bearing a longitudinal stria (Fig. 3F, arrow 1), a semicircular carina and pores (Fig. 3F, arrow 2), and a "sensory pad" with setae and glands (Fig. 3F, arrow 3). Metasternum (Fig. 4A): with a pair of setigerous patches (Fig. 4A, sp) just posterior to middle, each with 4 to 6 spinous setae (Fig. 4B). Leg: protibia slender and straight, with denticle at apical 1/5; mesotibia with denticle at apical 1/8. Genitalia: median lobe of aedeagus (Figs. 4E-4I) strongly sclerotized; basal bulb (Fig. 4F, bb) with small dorsal diaphragm (Fig. 4F, dd); inner sclerite (Fig. 4H, is) and apical process (Fig. 4H, ap) curved to the right in dorsal view. Parameres: right paramere (Fig. 4F, rp) shorter than left, broadened in apical $1 / 3$ and narrowed at apex, with a projection at apical $1 / 3$ of its outer margin; left paramere (Fig. 4F, lp) slender, twisted in basal 1/2, broadened apically. Female. Antenna: antennomere VII (Fig. 3G) about 1.1 times as long as wide, angulate at apical part (Fig. 3G, arrow), slightly depressed basimedially. 


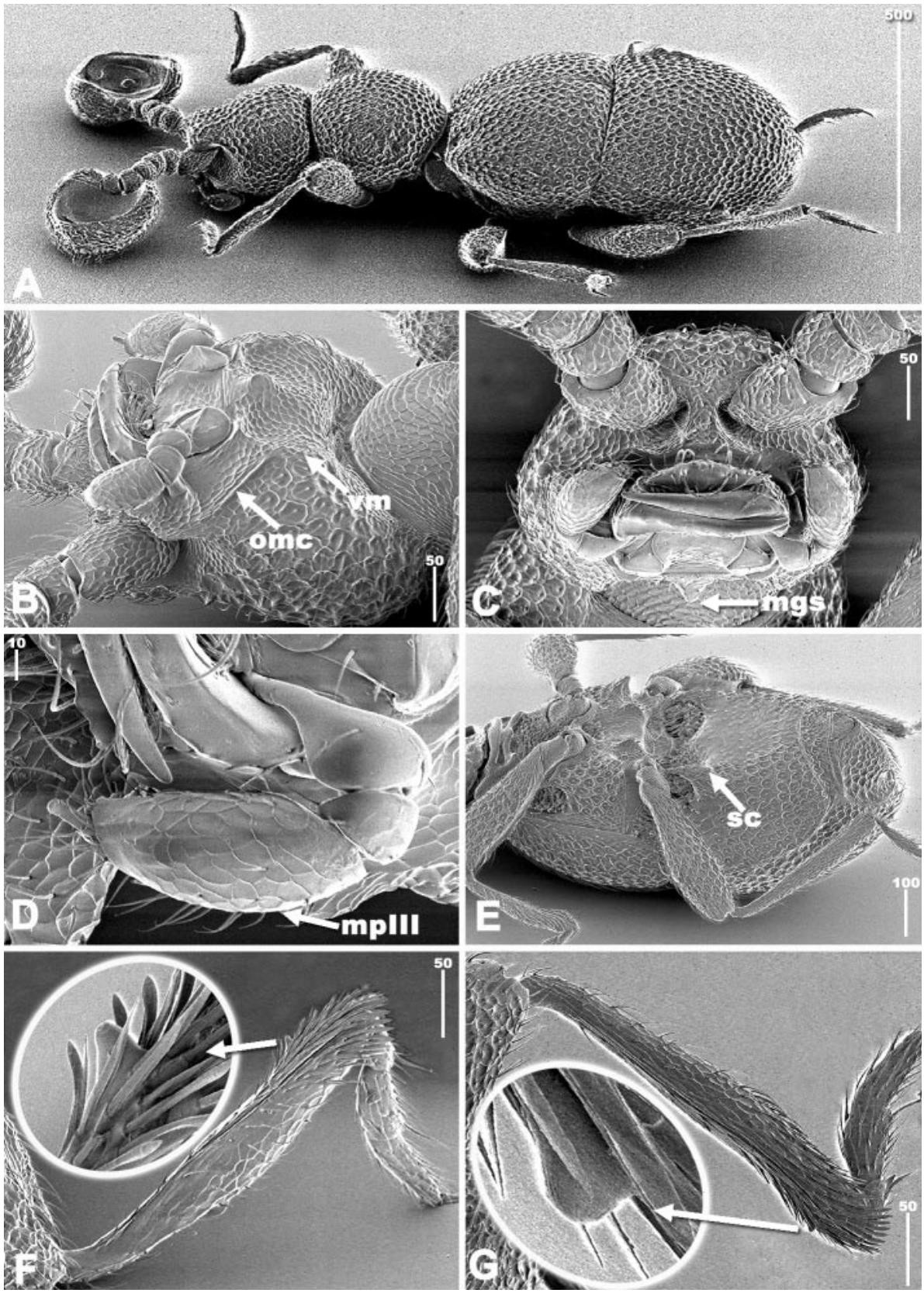

Figure 2. Plagiophorus hispidus (holotype). (A) Habitus, dorsolateral view; (B) head, ventrolateral view; (C) head, frontal view; (D) right maxillary palpus, ventral view; (E) metathorax, mesothorax, and abdomen, ventrolateral view; (F) left protibia, ventral view: arrow showing enlarged denticle; (G) left mesotibia, ventral view: arrow showing enlarged denticle. mgs, median gular spine; mpIII, maxillary palpomere III; omc, ocular-mandiblar carina; sc, sternal carina; vm, ventrolateral margin. Scale bars are in micrometres. 

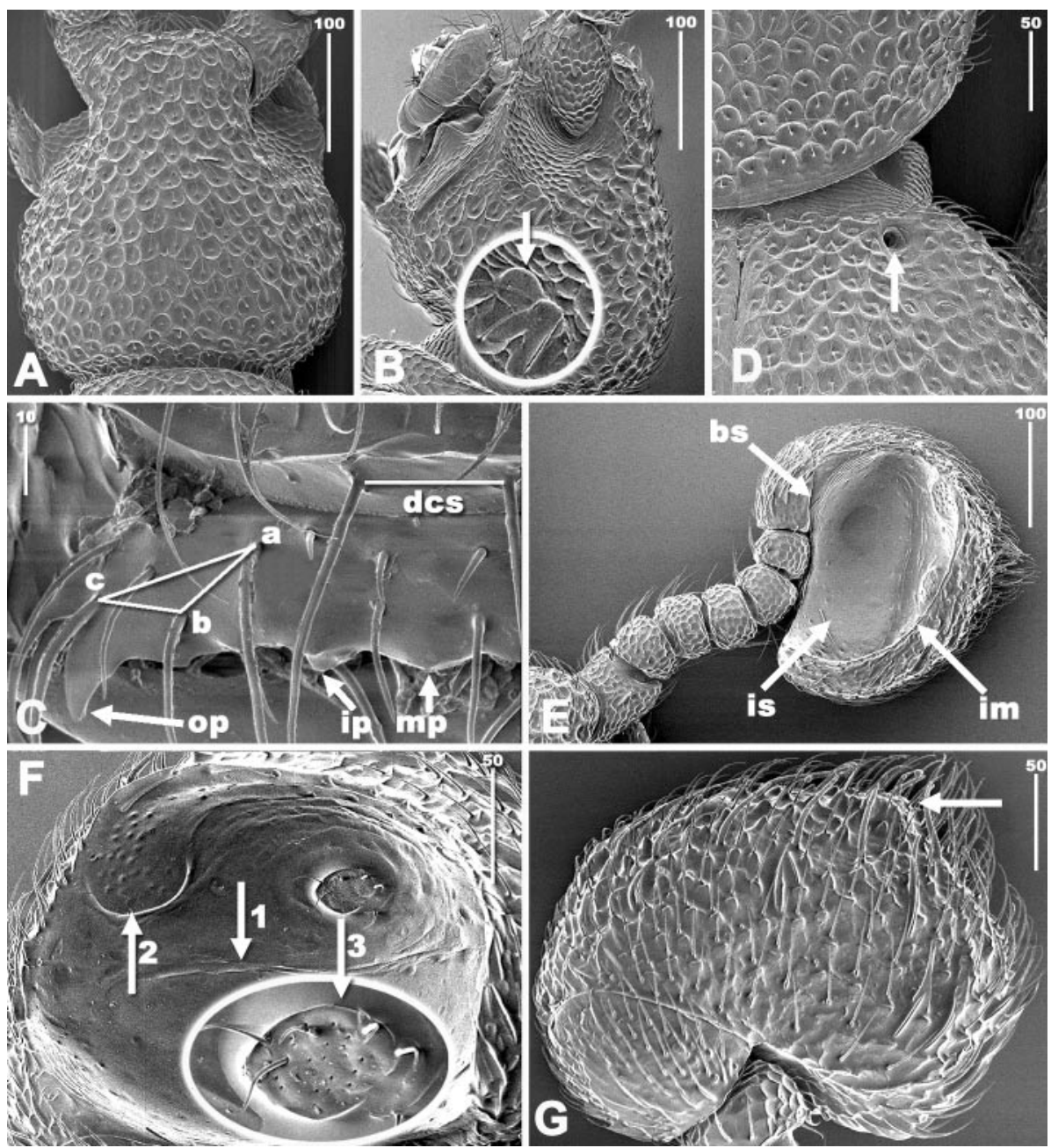

Figure 3. Plagiophorus hispidus (A-F, holotype, male; G, paratype, female). (A) Head, dorsal view; (B) head, lateral view: arrow showing enlarged eye; (C) chaetotaxy of labrum and clypeus; (D) right elytron, dorsal view: arrow indicating a basal fovea; (E) right antenna, dorsal view; (F) inner surface of right antennal club: arrow 1, longitudinal stria; arrow 2, semicircular carina; arrow 3, sensory pad; (G) right antennal club, dorsal view: arrow indicates angle. $a-c$, principal setae; bs, basal suture; dcs, distance between clypeal setae; im, inner margin; ip, inside projection of labrum; is, inner surface; mp, median projection of labrum; op, outside projection of labrum. Scale bars are in micrometres.

\section{Intraspecific variation}

The excavation on male antennomere VII is slightly shallower in the Iriomote Jima specimens than in those from Ishigaki Shima. These differences are interpreted as geographical variation.

\section{Distribution}

Japan (The Ryukyus: Ishigaki Shima and Iriomote Jima). Figure 12. 

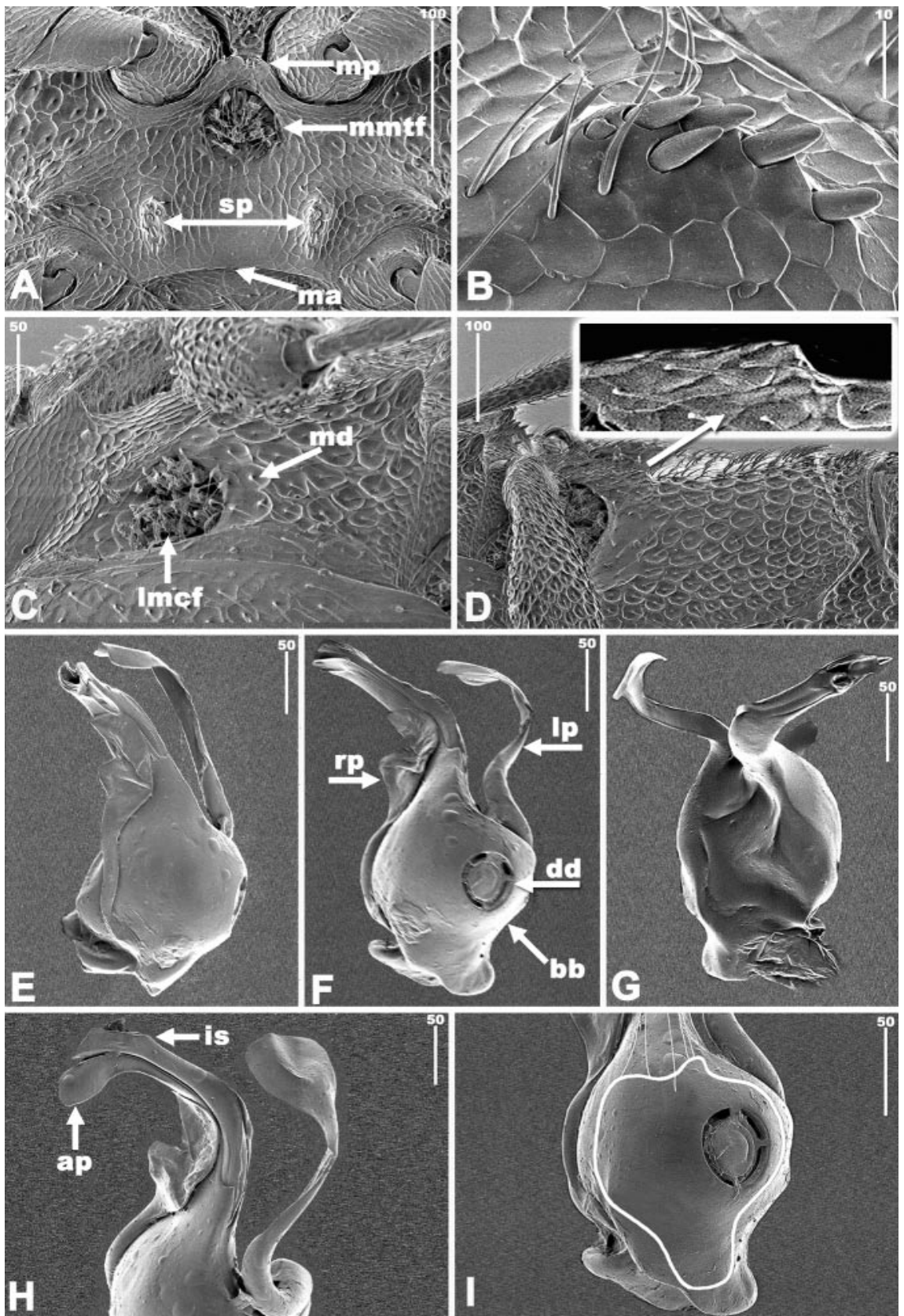

Figure 4. Plagiophorus hispidus (holotype, male). (A) Metasternum, ventral view; (B) right spinous setae at metasternum; (C) metasternum, lateral view; (D) sternal carina on abdomen, lateral view: arrow showing enlarged sternal carina; (E) aedeagus, lateral view; (F) aedeagus, dorsal view; (G) aedeagus, ventral view; (H) aedeagus, frontal-dorsal view; (I) basal bulb of aedeagus: white drawing showing inner structures, dorsal view. ap, apical process; bb, basal bulb; dd, dorsal diaphragm; is, inner sclerite; Imcf, lateral mesocoxal fovea; lp, left paramere; ma, metasternal apex; md, depression; mmtf, median metasternal fovea; mp, metasternal process; rp, right paramere; sp, setigerous patches. Scale bars are in micrometres. 


\section{Biological notes}

One of the authors, HS, collected specimens by sifting leaf litter from the natural evergreen forest in Ishigaki Shima and Iriomote Jima, which is dominated by Castanopsis sieboldii (Makino) (Fagaceae). He observed that male individuals walked with the excavation of the antennomere VII turned almost upward and often pulled antennomere VII through the protibiae and cleaned it with their mouthparts. They walked slowly and, when disturbed, rolled into a compact ball, "playing dead".

\section{Remarks}

Nomura (1986) misidentified this species as Paracyathiger matousheki Löbl 1964 (= Plagiophorus matousheki) and redescribed it on the basis of Japanese specimens. Our comparison of the present material with the type specimen of P. matousheki has revealed that it is the new species described above.

\section{Plagiophorus hlavaci sp. nov.}

(Figs. 1B, 5, 6, 12)

\section{Type material}

Holotype: male (Figs. 1B, 5A-5F, 5H, 5I, 6). CHINA. Fujian: Wuyi Shan, Nature Reserve Area, Sangan, 30.v.-12.vi.2001, P Hlavac and J Cooter (IZAS). Paratypes. Fujian: 3 males, 2 females, same data as holotype (cHS, private collection of J Cooter, private collection of P Hlavac). Zhejiang: 2 males, 1 female, Wuyanlin, Taishun, 11.xi.1990, Y Watanabe (NSMT).

\section{Etymology}

Dedicated to Peter Hlavac, a collector of the type material.

\section{Diagnosis}

This species is distinguished from the other members of the species group by the combination of the following character states in the male: $(i)$ frontal rostrum lacking longitudinal groove (Fig. 5A), (ii) eye with about 12 facets (Fig. 5B, arrow), (iii) antennomere III produced and angulate on inner margin, thus nearly pentagonal in profile (Fig. 5E, arrow; Fig. 5H), (iv) inner surface of antennal club lacking longitudinal stria (Fig. 5F), (v) each elytron with 2 basal foveae (Fig. 5D, arrows), and (vi) protibia with outer margin strongly constricted about middle (Fig. 5I, arrow).

\section{Description}

Male and female. Body (Fig. 1B). Length, 1.6-1.7 mm; width, 0.5-0.6 mm (see Table 1 for measurements of holotype); broadest at middle of elytra, dorsal surface shallowly favose-punctured. Head (Figs. 5A, 5B). Slightly wider than long (HW/HL = 1.15 ), broadest at posterior $1 / 3$; frontal rostrum flat in the median part, relatively wide $(\mathrm{HW} / \mathrm{FW}=2.11)$, arcuate at anterior margin; gena well expanded laterally. Labral and clypeal chaetotaxy (Fig. 5C): setal triangle with side $a-c$ about as long as dcs, side $b-c$ shortest. Labrum: ip more projecting than mp. Maxillary palpomere III: about twice as long as wide, distinctly reticulate on ventral surface. Thorax. Pronotum: longer than head $(\mathrm{PL} / \mathrm{HL}=1.15)$, broader than long $(\mathrm{PW} / \mathrm{PL}=1.05)$. Metasternum $($ Fig. $6 \mathrm{~A})$ : long, distance from metasternal process to metasternal apex about 3.4 times as long as longitudinal diameter of median metasternal fovea; metasternal process broadly truncate; 

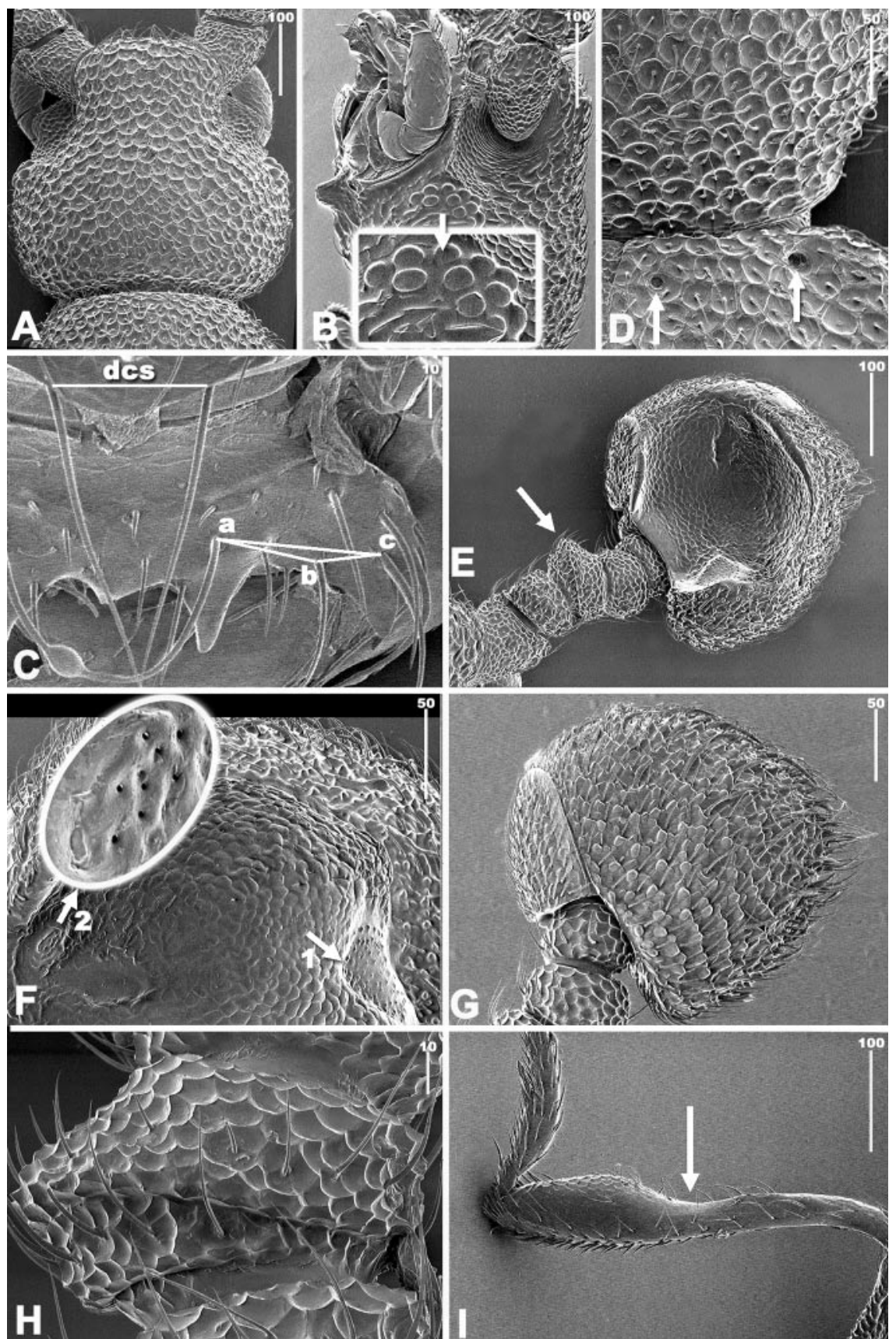

Figure 5. Plagiophorus hlavaci (A-F, holotype, male; G, paratype, female). (A) Head, dorsal view; (B) head, lateral view: arrow showing enlarged eye; (C) chaetotaxy of labrum and clypeus; (D) elytron, dorsal view: arrows indicating basal foveae; (E) right antenna, dorsal view: arrow indicating projection of antennomere III; (F) inner surface of right antennal club: arrow 1, triangular depression; arrow 2, sensory pad; (G) right antennal club, dorsal view; (H) right antennomere III, dorsal view; (I) right protibia, dorsal view: arrow indicating constriction. $a-c$, principal setae; des, distance between clypeal setae. Scale bars are in micrometres. 

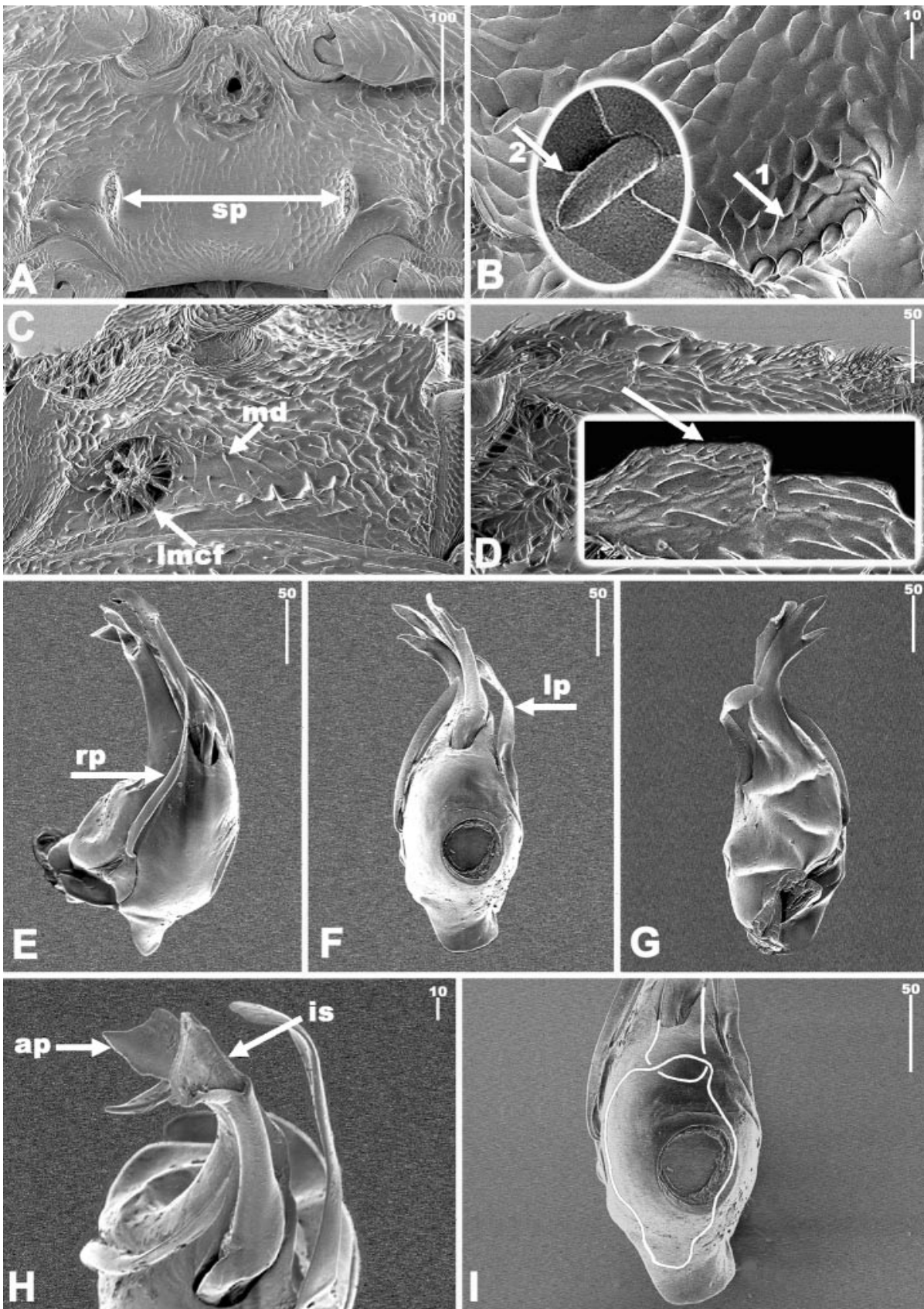

Figure 6. Plagiophorus hlavaci (holotype, male). (A) Metasternum, ventral view; (B) right spinous setae at metasternum: arrows 1 and 2, setigerous patches; (C) metasternum, lateral view; (D) sternal carina on abdomen, lateral view: arrow indicating enlarged sternal carina; (E) aedeagus, lateral view; (F) aedeagus, dorsal view; (G) aedeagus, ventral view; (H) aedeagus, frontal-dorsal view; (I) basal bulb of aedeagus: white drawing showing inner structures, dorsal view. ap, apical process; is, inner sclerite; Imcf, lateral mesocoxal fovea; lp, left paramere; md, depression; rp, right paramere; sp, setigerous patches. Scale bars are in micrometres. 
lateral mesocoxal fovea almost circular (Fig. 6C, lmcf); depression around lateral mesocoxal fovea extending posteriorly to posterior $1 / 3$ of metasternum (Fig. 6C, md). Elytra: longer than abdomen $(\mathrm{EL} / \mathrm{AL}=1.18)$, broader than long $(\mathrm{EW} / \mathrm{EL}=1.33)$, broadest at middle, convex, each elytron with 2 basal foveae (Fig. 5D, arrows); hind wing reduced. Leg: metatibia slightly sinuate. Abdomen. Composite tergum wider than long $(\mathrm{AW} / \mathrm{AL}=1.49)$, broadest just behind base; composite sternum shallowly concave at median part.

Sexual characters. Male. Eye with about 12 facets (Fig. 5B, arrow). Antenna (Fig. 5E): antennomere III (Fig. 5E, arrow; Fig. 5H) about 1.9 times as wide as long, produced and angulate on inner margin, thus nearly pentagonal in profile, with 2 indistinct sutures; antennomeres V and VI partly covered by VII in dorsal view; antennomere VII (Fig. 5F) about 1.2 times as long as wide, reniform, its excavation open basimedially, inner surface reticulate, bearing a triangular depression (Fig. 5F, arrow 1) and small sensory pad with pores (Fig. 5F, arrow 2). Metasternum (Fig. 6A): pair of setigerous patches (Fig. 6A, sp) situated posterior to middle, each with 4 to 7 spinous setae (Fig. 6B, arrow 1). Leg: protibia with outer margin strongly constricted about middle (Fig. 5I, arrow), with denticle at apical 1/5; mesotibia with denticle at apical 1/12. Abdomen with composite sternum: flattened at posterior $1 / 3$; sternal carina with 2 teeth, anterior tooth weakly convex and situated at apical 1/3, posterior tooth just posterior to anterior tooth and lower and shorter than anterior tooth (Fig. 6D). Genitalia: median lobe of aedeagus (Figs. 6E-6I) strongly sclerotized; basal bulb with small dorsal diaphragm; inner sclerite (Fig. 6H, is) curved to right, its apical part depressed; apical process (Fig. 6H, ap) slightly shorter than inner sclerite, curved to right in dorsal view, its apical part forked. Parameres: right paramere shorter than left, slender, curved inwardly in dorsal view (Fig. 6E, rp); left paramere slender, basal 1/2 curved inwardly in dorsal view (Fig. 6F, lp). Female. Eye with 3 to 4 facets. Antenna: antennomere III less angular than that of male; antennomere VII about as long as wide, slightly depressed on basimedial margin (Fig. 5G). Abdominal sternal carina with tooth lower than that in male.

\title{
Intraspecific variation
}

Holotype has 1 extra spinous seta, which is situated behind the right setigerous patch (Fig. 6B, arrow 2).

\section{Distribution}

China (Fujian sheng, Zhejiang sheng). Figure 12.

\section{Plagiophorus serratus sp. nov.}

\author{
(Figs. 1C, 7, 8, 12)
}

\section{Type material}

Holotype: male (Figs. 1C, 7, 8). CHINA. Yunnan: Huanxipo, $1750 \mathrm{~m}$ alt., Tengchong, 14.x.1996, S Nomura (NSMT).

\section{Etymology}

The Latin serratus meaning serrate, in reference to the serrate teeth on the sternal carina. 

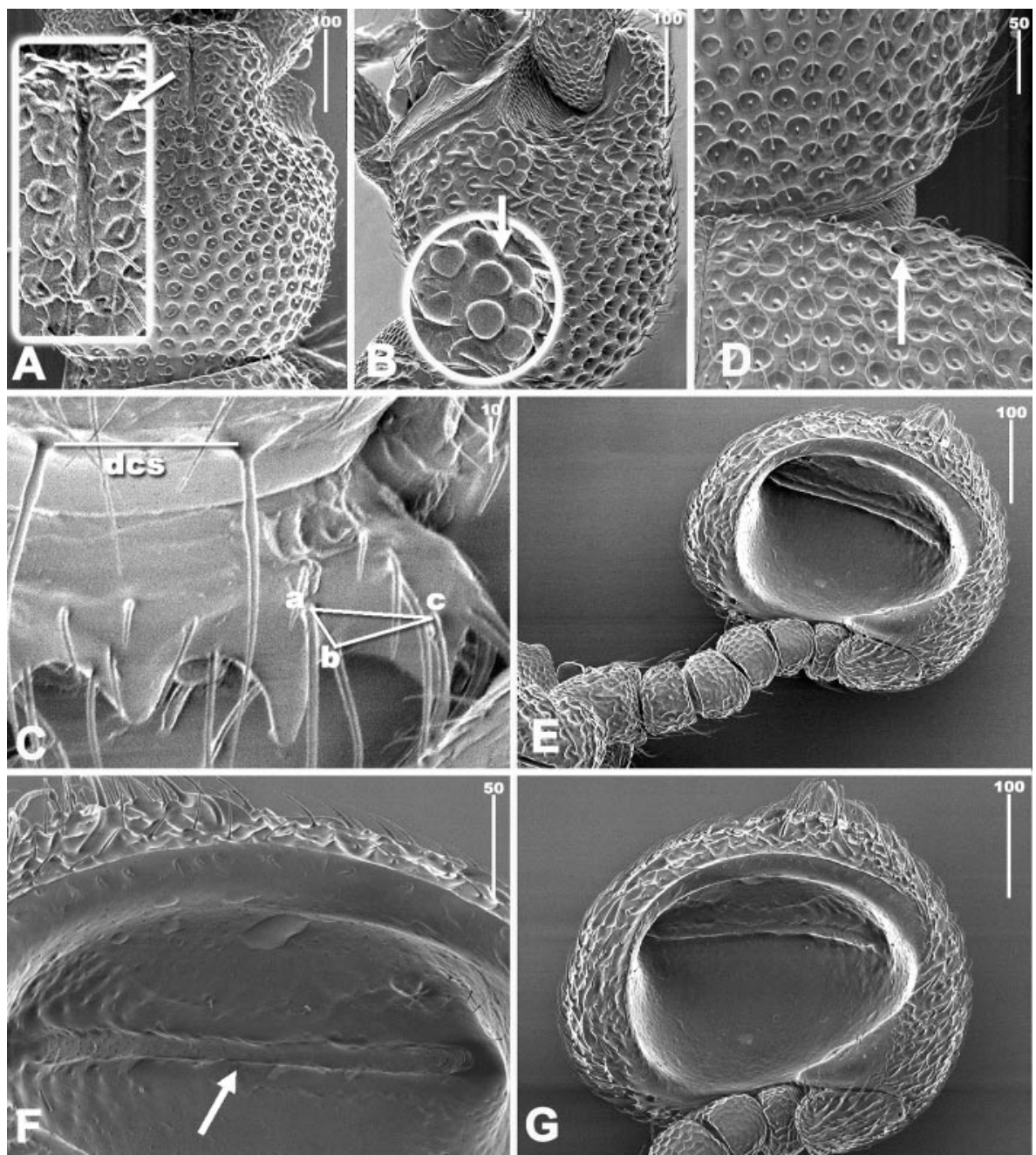

Figure 7. Plagiophorus serratus (holotype, male). (A) Head, dorsal view: arrow showing enlarged groove; (B) head, lateral view: arrow showing enlarged eye; (C) chaetotaxy of labrum and clypeus; (D) elytron, dorsal view: arrow indicating basal fovea; (E) left antenna, dorsal view; (F) left inner surface of antennal club: arrow indicating longitudinal stria; (G) left antennal club. $a-c$, principal setae; dcs, distance between clypeal setae. Scale bars are in micrometres.

\section{Diagnosis}

This species is distinguished from the other members of the species group by the combination of the following character states in the male: $(i)$ frontal rostrum with a longitudinal groove (Fig. 7A, arrow), (ii) eye with about 7 facets (Fig. 7B, arrow), (iii) inner surface of antennal club with a longitudinal stria (Fig. 7F, arrow), (iv) each elytron with a basal fovea (Fig. 7D, arrow), and (v) sternal carina with 4 teeth (Fig. 8D, arrow).

\section{Description}

Male (holotype). Body. Length (TL), $1.7 \mathrm{~mm}$; width (EW), $0.7 \mathrm{~mm}$ (see Table 1 for measurements of holotype); broadest at posterior $1 / 3$ of elytra, densely covered in 

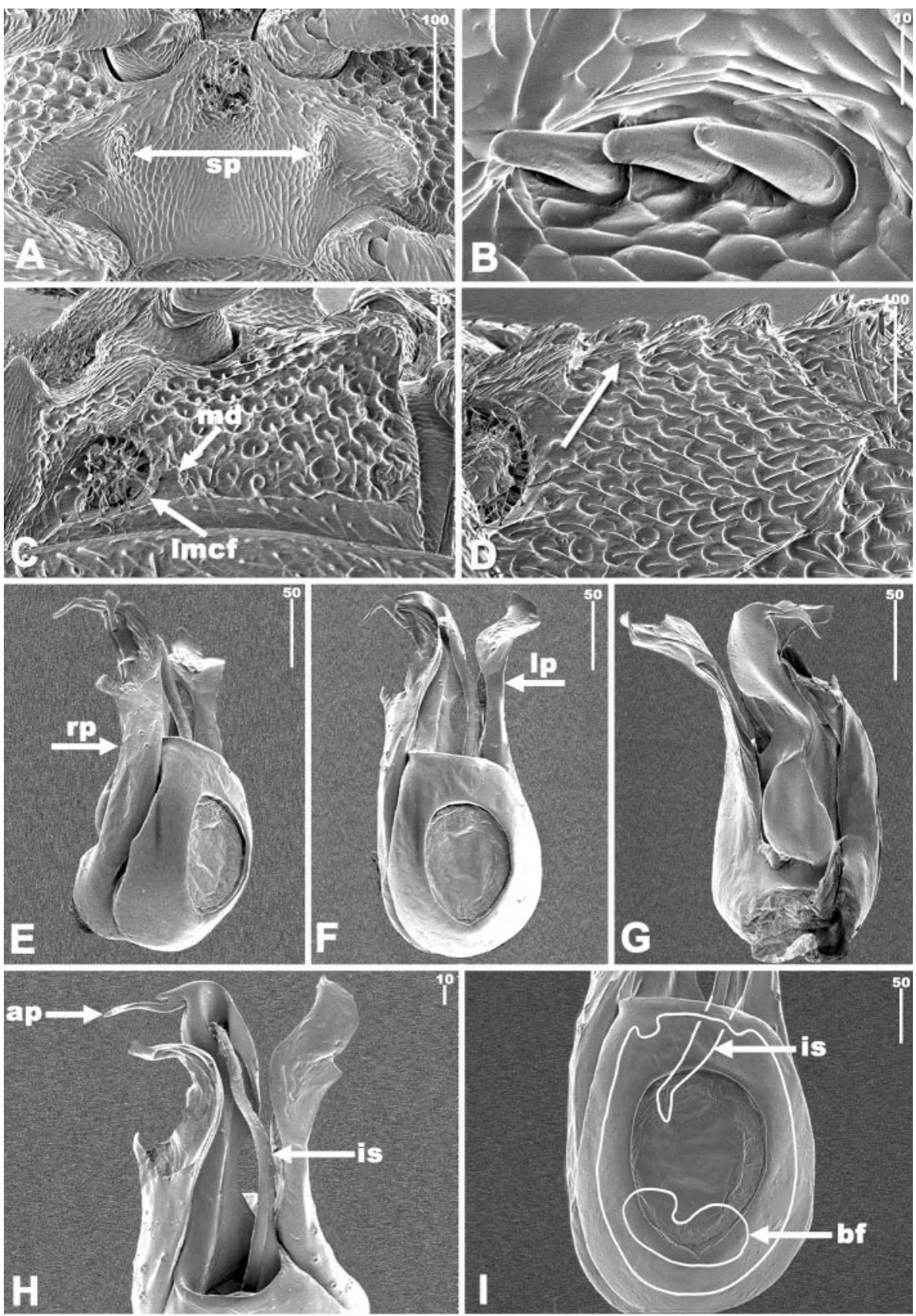

Figure 8. Plagiophorus serratus (holotype, male). (A) Metasternum, ventral view; (B) left spinous setae at metasternum; (C) metasternum, lateral view; (D) sternal carina on abdomen, lateral view: arrow showing enlarged sternal carina; (E) aedeagus, lateral view; (F) aedeagus, dorsal view; (G) aedeagus, ventral view; (H) aedeagus, frontal-dorsal view; (I) basal bulb of aedeagus: white drawing showing inner structures, dorsal view. ap, apical process; bf, basal foramen; is, inner sclerite; Imcf, lateral mesocoxal fovea; Ip, left paramere; rp, right paramere; sp, setigerous patches. Scale bars are in micrometres. 
fine punctures dorsally. Head (Figs. 7A, 7B). Slightly longer than wide (HW/HL = $0.95)$, broadest at middle; frontal rostrum relatively narrow $(\mathrm{HW} / \mathrm{FW}=1.75)$, bisinuate on anterior margin, with a deep longitudinal groove (Fig. 7A, arrow); gena expanded anterolaterally; eye reduced, with about 7 facets (Fig. 7B, arrow). Labral and clypeal chaetotaxy (Fig. 7C): setal triangle with side $a-c$ shorter than des; side $a-b$ shortest. Labrum: ip distinctly projecting and longer than op. Maxillary palpomere III: 2.2 times as long as wide, distinctly reticulate on ventral surface. Antenna (Fig. 7E): antennomere III about 1.2 times as wide as long, with 2 indistinct sutures; antennomere VI partly covered by VII in dorsal view; antennomere VII (Fig. 7F) about 1.2 times as long as wide, nearly ovate, inner surface with a longitudinal stria (Fig. 7F, arrow), almost glabrous except around longitudinal stria. Thorax. Pronotum: longer than head $(\mathrm{PL} / \mathrm{HL}=$ 1.11), broader than long $(\mathrm{PW} / \mathrm{PL}=1.12)$. Metasternum $($ Fig. $8 \mathrm{~A})$ : long, distance from metasternal process to metasternal apex about 3.7 times as long as longitudinal diameter of median metasternal fovea; metasternal process broad and truncate; with pair of setigerous patches just anterior to middle (Fig. 8A, sp); each setigerous patch with 3 spinous setae (Fig. 8B); lateral mesocoxal fovea almost circular (Fig. 8C, lmcf); depression around lateral mesocoxal foveae not extending posteriorly (Fig. 8C, md). Elytra: longer than abdomen $(\mathrm{EL} / \mathrm{AL}=1.17)$, broader than long $(\mathrm{EW} / \mathrm{EL}=1.37)$, convex, broadest at middle, each elytron with basal fovea (Fig. 7D, arrow); hind wing reduced. Leg: protibia slender and straight, with denticle at apical 1/5; mesotibia with denticle at apical 1/6, sinuate at middle and curved inwardly at apex; metatibia distinctly sinuate. Abdomen. Long, composite tergum wider than long $(\mathrm{AW} / \mathrm{AL}=1.54)$, broadest at basal $1 / 4$; composite sternum shallowly concave medially; sternal carina (Fig. 8D) with 4 teeth of equal height. Genitalia: median lobe of aedeagus (Figs. 8E-8I) strongly sclerotized; basal bulb with large dorsal diaphragm; inner sclerite slender, arising from inside of posterior $1 / 3$ of basal bulb (Fig. 8I, is), curved inwardly in dorsal view (Fig. $8 \mathrm{H}$, is); apical process longer than inner sclerite, stout, constricted at middle, apical part with needle-shaped projection (Fig. 8H, ap). Parameres: right paramere shorter than left, stout, with projection at apical $1 / 4$, its apical part curved outward in dorsal view (Fig. 8E, rp); left paramere stout, markedly broad at apical $1 / 3$, forked laterally (Fig. 8F, lp).

Female. Unknown.

\section{Distribution}

China (Yunnan sheng). Figure 12.

\section{Remarks}

We could not define sexual characters because no female specimen was available for comparison in this study.

\section{Plagiophorus grandoculatus sp. nov.}

(Figs. 9, 10, 12)

\section{Type material}

Holotype: male (Figs. 9, 10). CHINA. Yunnan: Menglien, Tengchong, 15.x.1996, S Nomura (NSMT). 


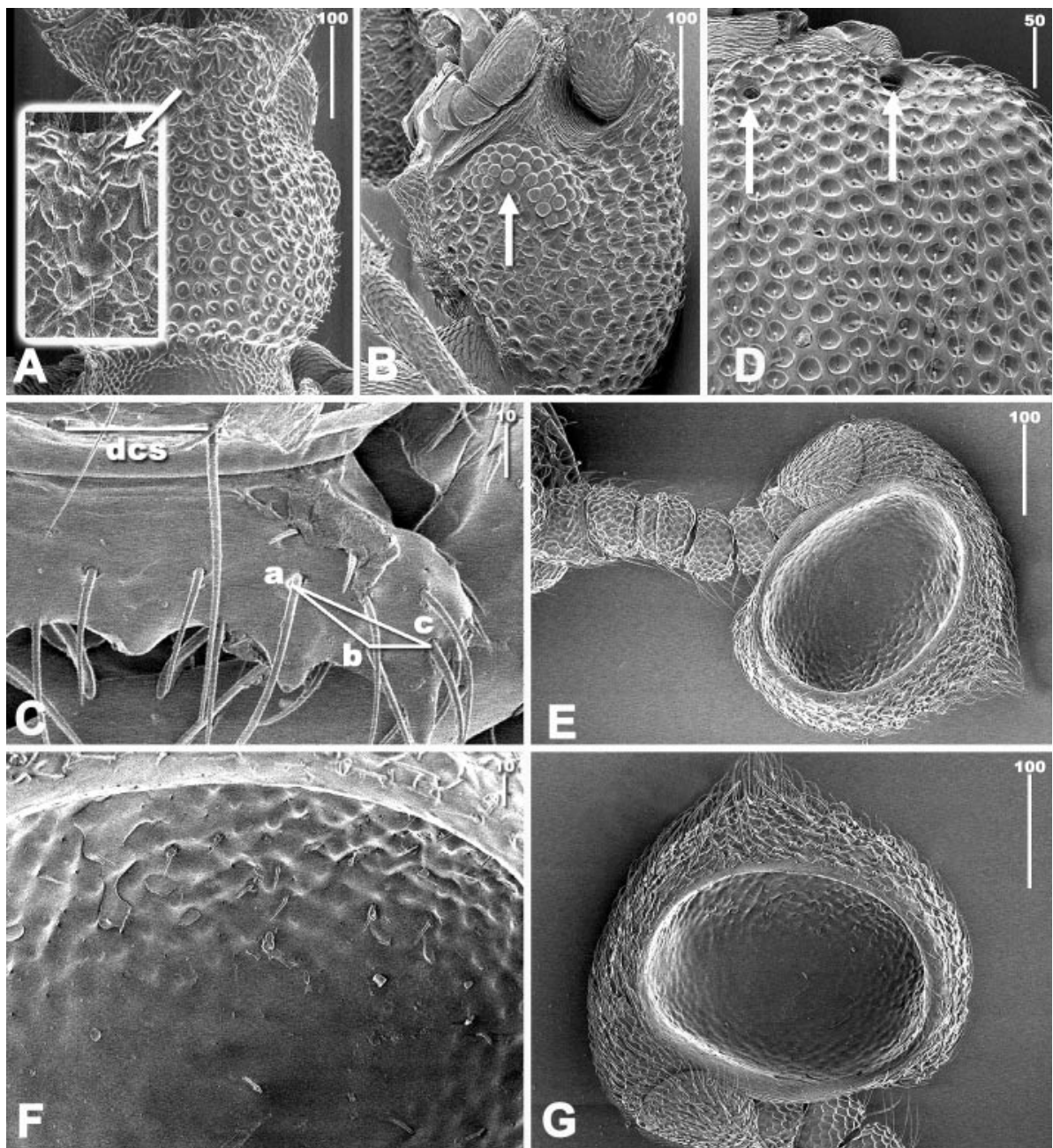

Figure 9. Plagiophorus grandoculatus (holotype, male). (A) Head, dorsal view: arrow showing enlarged groove; (B) head, lateral view: arrow showing enlarged eye; (C) chaetotaxy of labrum and clypeus; (D) elytron, dorsal view: arrows indicating basal foveae; (E) right antenna, dorsal view; (F) inner surface of right antennal club; (G) right antennal club. $a-c$, principal setae; dcs, distance between clypeal setae. Scale bars are in micrometres.

\section{Etymology}

The Latin grandoculatus means large eye.

\section{Diagnosis}

This species is distinguished from the other members of the species group by the combination of the following character states in the male: $(i)$ frontal rostrum with a longitudinal groove (Fig. 9A, arrow), (ii) eye reniform with about 40 facets (Fig. 9B), (iii) inner surface of antennal club lacking longitudinal stria (Fig. 9F), (iv) each elytron with 2 basal foveae (Fig. 9D, arrows), and (v) sternal carina with a weak tooth located at apical 2/5 (Fig. 10D). 

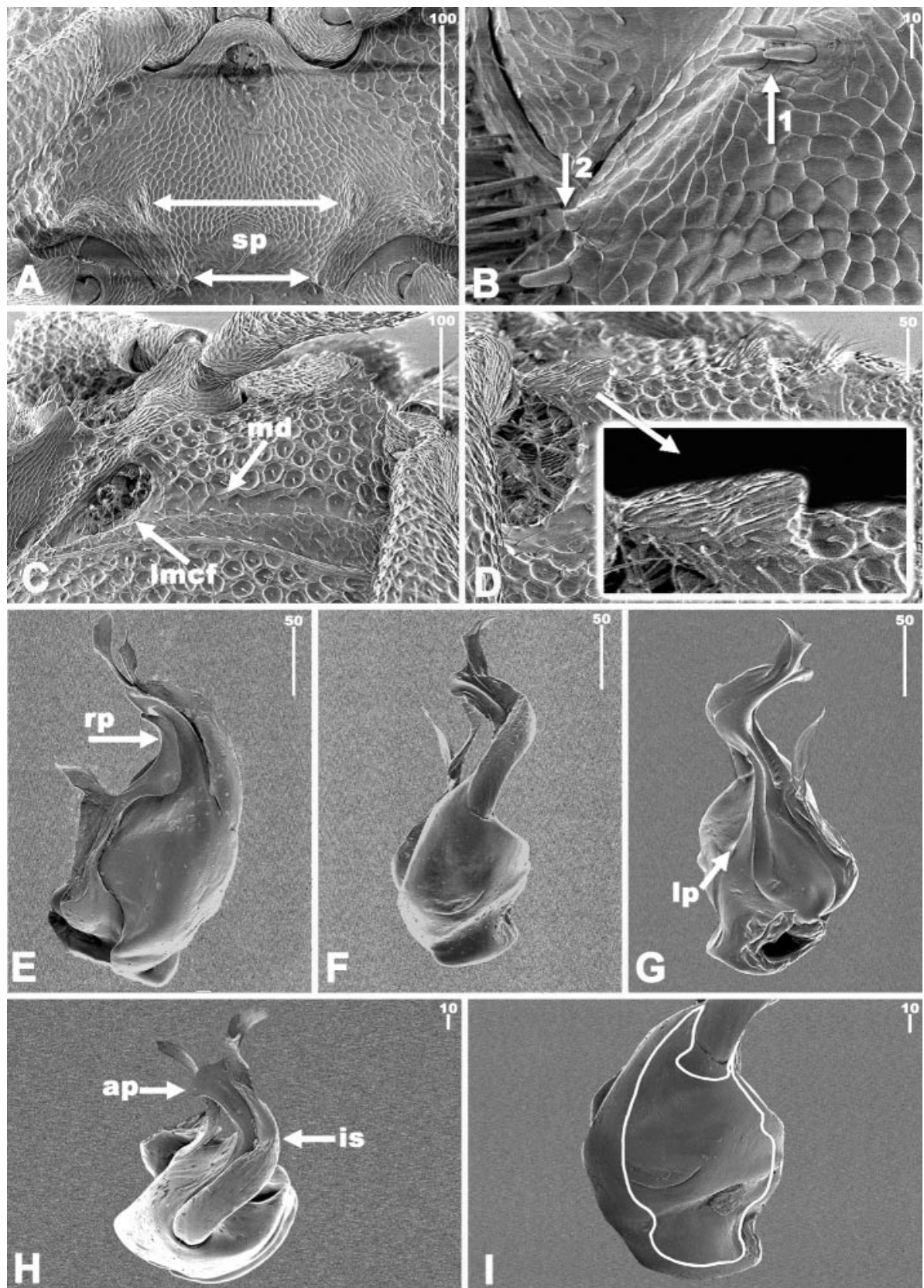

FigURE 10. Plagiophorus grandoculatus (holotype, male). (A) Metasternum, ventral view; (B) left spinous setae at metasternum: arrow 1, anterior setigerous patch; arrow 2, posterior setigerous patch; (C) metasternum, lateral view; (D) sternal carina on abdomen, lateral view: arrow showing enlarged sternal carina; (E) aedeagus, lateral view; (F) aedeagus, dorsal view; $(G)$ aedeagus, ventral view; (H) aedeagus, frontal-dorsal view; (I) basal bulb of aedeagus: white drawing showing inner structures, dorsal view. ap, apical process; is, inner sclerite; Imcf, lateral mesocoxal fovea; lp, left paramere; md, depression; rp, right paramere; sp, setigerous patches. Scale bars are in micrometres. 


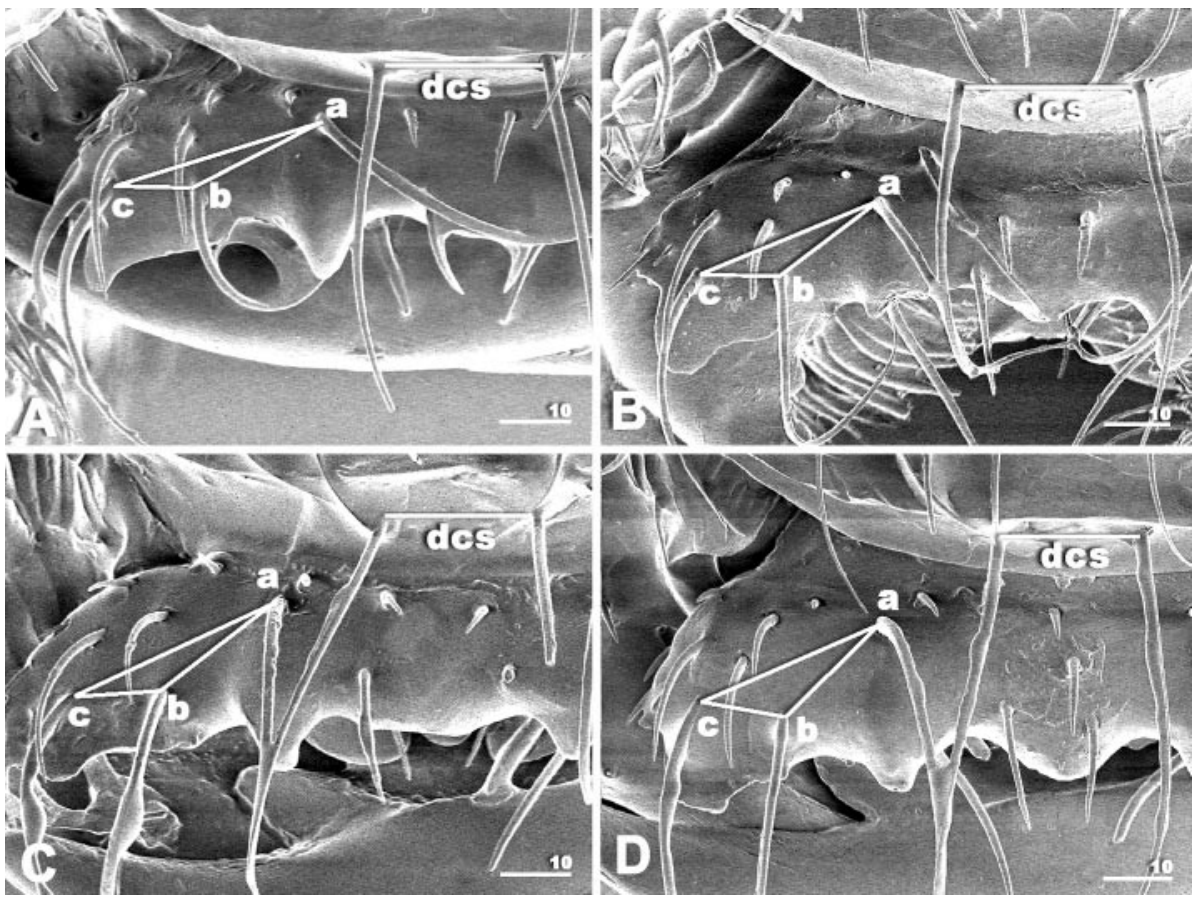

Figure 11. Chaetotaxy of labrum and clypeus of Plagiophorus hispidus (paratypes). (A) male, Ishigaki Shima; (B) female, Ishigaki Shima; (C) male, Iriomote Jima; (D) female, Iriomote Jima. $a-c$, principal setae; dcs, distance between clypeal setae. Scale bars are in micrometres.

\section{Description}

Male (holotype). Body. Length, $1.7 \mathrm{~mm}$; width, $0.7 \mathrm{~mm}$ (see Table 1 for measurements of holotype); broadest at anterior 1/3 of abdomen, densely covered with fine punctures dorsally. Head (Figs. 9A, B). Slightly longer than wide $(\mathrm{HW} / \mathrm{HL}=0.94)$, broadest at posterior $1 / 3$; frontal rostrum relatively narrow $(\mathrm{HW} / \mathrm{FW}=1.79)$, distinctly bisinuate on anterior margin, with shallow longitudinal groove (Fig. 9A, arrow); gena well expanded anterolaterally; eye reniform with about 40 facets (Fig. 9B). Labral and clypeal chaetotaxy (Fig. 9C): setal triangle with side $a-c$ longer than dcs; side $b-c$ shortest. Labrum: ip more projecting than $\mathrm{mp}$ and shorter than op. Maxillary palpomere III: about 2.1 times as long as wide, distinctly reticulate on ventral surface. Antenna (Fig. 9E): antennomere III about 1.3 times as wide as long, with 2 indistinct sutures; antennomere VI partly covered by VII in dorsal view; antennomere VII (Fig. 9G) about 1.1 times as long as wide, nearly ovate, inner surface granulate on peripheral portion (Fig. 9F). Thorax. Pronotum: longer than head $(\mathrm{PL} / \mathrm{HL}=1.06)$, broader than long $(\mathrm{PW} / \mathrm{PL}=1.05)$. Metasternum: long (Fig. 10A), distance from metasternal process to metasternal apex about 6.2 times as long as longitudinal diameter of median metasternal fovea; metasternal process broad and rounded; with 2 pairs of setigerous patches (Fig. 10A, sp) just posterior to middle and near posterior margin, the anterior pair each with 3 to 5 spinous setae (Fig. 10B, arrow 1), the posterior pair with 1-2 spinous setae (Fig. 10B, arrow 2); lateral mesocoxal foveae elliptical (Fig. 10C, lmcf); depression around lateral mesocoxal foveae narrowed posteriorly and extending to just anterior to metacoxa (Fig. 10C, md). Elytra: longer than abdomen $(\mathrm{EL} / \mathrm{AL}=1.30)$, broader than long $(\mathrm{EW} / \mathrm{EL}=1.40)$, convex, broadest at middle, each elytron with 2 basal foveae (Fig. 9D, arrows); hind wing developed. Leg: protibia slender and straight, with denticle 


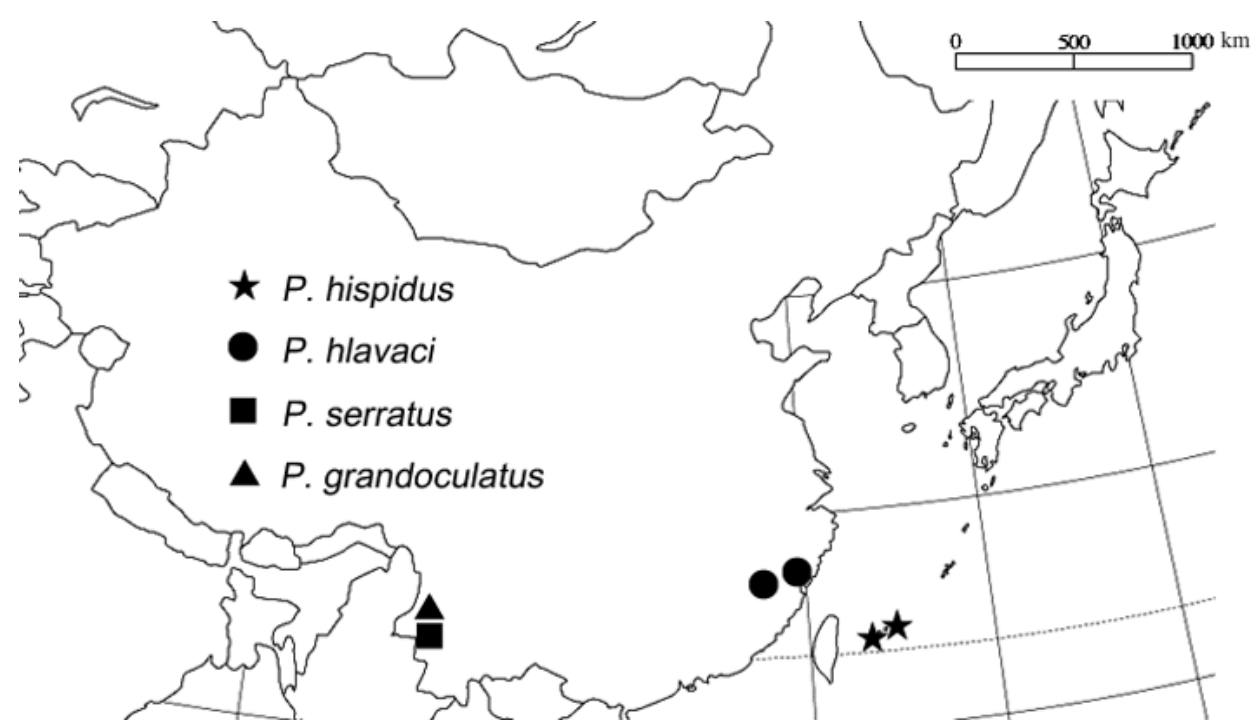

Figure 12. Map of distribution of Plagiophorus species of the hispidus group.

at apical 1/4; mesotibia with denticle just before apex; metatibia distinctly sinuate. Abdomen. Composite tergum wider than long $(\mathrm{AW} / \mathrm{AL}=1.68)$, broadest at basal $1 / 5$; composite sternum deeply excavated at median part; sternal carina with weak tooth located at apical 2/5 (Fig. 10D). Genitalia: median lobe of aedeagus (Figs. 10E-10I) weakly sclerotized; inner sclerite stout, S-shaped in dorsal view, gradually narrowed from middle to apex (Fig. 10H, is); apical process longer than inner sclerite, stout, Sshaped in dorsal view, with wide projection at apical $1 / 3$ of outer margin (Fig. 10H, ap). Parameres: right paramere stout, shorter than left, constricted at middle, curved outward apically (Fig. 10E, rp); left paramere, long (Fig. 10G, lp).

Female. Unknown.

\section{Distribution}

China (Yunnan sheng). Figure 12.

\section{Remarks}

We could not define sexual characters because no female specimen was available for comparison in this study.

\section{Acknowledgments}

We thank J Jelínek (National Museum, Prague, Czech Republic) for his help with the type specimen of P. matousheki. We also thank C Besuchet, G Cuccodoro, and I Löbl (MHNG); DS Chandler (The University of New Hampshire, United States of America); P Hlavac (Košice, Slovakia); H Hoshina (Fukui University, Fukui, Japan); and M Kubota (Kanagawa, Japan) for their valuable suggestions and the loan of material. HS thanks M Suwa, S Takagi, and M Maruyama (SEHU) for critically reading the original manuscript; T Yoshida (SEHU) for his assistance; T Itô (Electron Microscope Laboratory, Graduate school of Agriculture, Hokkaido University, Sapporo, Japan) and M Ôhara (The Hokkaido University Museum, Sapporo, Japan) for their technical guidance for SEM observations; and M Kinjo (University of the Ryukyus, Okinawa, Japan) 
for his field assistance in Iriomote Jima. The fieldwork of SN was supported by Grantin-aid 09041167 for Field Research of the Monbusho International Scientific Research Program, Japan.

\section{References}

Burckhardt D. 1985. Beitrag zur Kenntnis der Cyathigerini von Malaysia und Singapore (Coleoptera, Pselaphidae). Revue Suisse de Zoologie 92(1): 255-70

-1988a. The genus Cyathiger King from the Solomon Islands (Coleoptera: Pselaphidae). Mitteilungen der Schweizerischen Entomologischen Gesellschaft 61: 131-4

_ 1988b. On some Australian species of Cyathiger King (Coleoptera: Pselaphidae). Revue Suisse de Zoologie 95(2): 385-90

Burckhardt D, Löbl I. 2002. Redescription of Plagiophorus paradoxus Motschulsky with comments on the pselaphine tribe Cyathigerini (Coleoptera: Staphylinidae). Revue Suisse de Zoologie 109(2): 397-406

Chandler DS. 1986. A revision of the genus Cyathiger (Coleoptera: Pselaphidae). Australian Entomological Magazine 12(6): 119-24

2001. Biology, morphology and systematics of the ant-like litter beetles of Australia (Coleoptera: Staphylinidae: Pselaphinae). Memoirs on Entomology International 15: 560

Jeannel R. 1951. Psélaphides de l'Angola (Coléoptères) recueillis par M. A. de Barros Machado. Companhia de Diamantes de Angola (Diamang). Servicos Culturais, Publicacoes Culturais 9: 1-125

1952. Psélaphides recueillis par N. Leleup au Congo Belge. IV. Faune de l'Itombwe et de la Forêt du Rugege. Annales du Musee Royal du Congo Belge 11: 1-295

1953. Psélaphides recueillis par N. Leleup au Congo Belge. V. Faune de l'Itombwe-Sud, du Kahuzi, de la dorsale de Lubero et du Mont Hoyo. Annales du Musee Royal du Congo Belge 20: 1-313

- 1954. Psélaphides recueillis par N. Leleup au Congo Belge sous les auspices de l'Institut pour la Recherche Scientifique en Afrique Centrale (I.R.S.A.C.) VI-XI. Annales du Musee Royal du Congo Belge 33: $1-174$

1956. Psélaphides recueillis par N. Leleup au Congo Belge sous les auspices de l'Institut pour la Recherche Scientifique en Afrique Centrale (I.R.S.A.C.) XII-XV. Annales du Musee Royal du Congo Belge 43: 1-134

- 1957. Sur quelques Psélaphides du Tonkin recueillis par le père A. de Cooman. Revue Francaise d'Entomologie 24(1): 5-32

1959. Révision des Psélaphides de l'Afrique intertropicale. Annales du Musee Royal du Congo Belge 75: $1-742$

1960. Psélaphides recueillis par N. Leleup au Congo Belge sous les auspices de l'Institut pour la Recherche Scientifique en Afrique Centrale (I.R.S.A.C.) XVI-XVIII. Annales du Musee Royal du Congo Belge 83: 1-181

- 1961. Sur les Psélaphides de Ceylan. Bulletin of the British Museum (Natural History) Entomology 10(10): 423-56

King RL. 1865. On the Pselaphidae of Australia. Transactions of the Entomological Society of New South Wales 1: 167-75

Kubota M. 1944. New and little known Pselaphidae from Japan. Transactions of the Kansai Entomological Society 14(1): 6-11

Leleup N. 1974. Contributions à l'étude des Coléoptères Psélaphides de l'Afrique. 15. Révision et position systématique du genre Cyathigerodes Jeannel (Bythininae, Cyathigerini). Revue de Zoologie Africaine 88(3): $625-73$

1975. Contributions à l'étude des Coléoptères Psélaphides de l'Afrique. 17. Deux Cyathigerodes anophthalmes nouveaux du Ruwenzori (Bythininae, Cyathigerini). Revue de Zoologie Africaine 89 (1): $113-6$

Leschen R, Löbl I. 1995. Phylogeny of Scaphidiinae with redefinition of tribal and generic limits (Coleoptera: Staphylinidae). Revue Suisse de Zoologie 102(2): 425-74

Löbl I. 1964. Zwei neue Pselaphiden-Arten aus China (Coleoptera). Reichenbachia 2: 297-300

Motschulsky VE. 1851. Énumération des nouvelles espèces de coléoptères rapportés par M. Victor Motschulsky de son dernier voyage. Bulletin de la Societe Imperiale des Naturalistes de Moscou 24 : 480-511

Newton AF, Chandler DS. 1989. World catalog of the genera of Pselaphidae (Coleoptera). Fieldiana Zoology New Series 53: 1-93

Nomura S. 1989. Taxonomic study on the genus Paracyathiger (Coleoptera, Pselaphidae) from Japan. Japanese Journal of Entomology 57(3): 527-32

Ohishi H. 2001. Notes on the mouthparts of Pselaphinae (Coleoptera: Staphylinidae). pp 37-46 in Insecta Miyatakeana. Osaka, Japan: Entomological Laboratory, Osaka Museum of Natural History [In Japanese] 
Raffray A. 1904. Genera et catalogue des Psélaphides. Annales de la Societe Entomologique de France 73: $1-400$

1908. Coleoptera. Fam. Pselaphidae. pp 1-487 in P Wytsmann (Ed), Genera Insectorum 64. Rome: Fascicule

1911. Pselaphidae. pp 1-222 in S Schenkling (Ed), Coleopterorum catalogus, pars 27. Berlin: W Junk Publishers

Sawada K. 1972. Methodological research in the taxonomy of Aleocharinae. Contributions from the Biological Laboratory Kyoto University 24: 31-59

Schaufuss LW. 1872. Tabellen-Entwurf zur Bestimmung der Pselaphiden-Gattungen. Nunquam Otiosus 2: 241-8

(Received: 17 January 2003; accepted: 11 August 2003) 